provided for removing any deposit that accumulated in these pipes or nozzles. The low-water alarm whistles were found to have been gagged so that, no matter how low the water became, the whistles could not sound. The arrangement of the steam main was also faulty, as it kept up a continual vibration. Possibly the explosion of the boiler in December was due to one of these causes.

\title{
RECENT DEVELOPMENTS AT THE NIAGARA FALLS POWER PLANT.
}

Perhaps the most interesting of late improvements at the great power plant on the upper Niagara is the completed aluminium transmission line to Buffalo by means of which electric current will be sent to Pan-American Exposition for all the manifold purposes for which electricity will be brought into use. Not the least noteworthy, also, are the changes in the lightning arrester er with the installation of circuitbreakers on the 22 kilo-volt line.

These lightning arresters (Fig. 2) are made by the Westinghouse Electric and Manufacturing pany. The spark gaps for each of the three lines are on marble slabs upon three sides of a wooden frame set on rollers. Thus, in case of total di sa bility. the lightning arrester may be rolled out and another substituted for it.

A three-phase General Elecground detector surmounts each lightning arrester frame. At the top of each marble slab is an auxiliary air gap, set according to the line voltage. For 25,000 volts, the ap is one-fourth gap is one 23,000 volts, one - eighth inch; while for 21,000 volts there is no gap. Below this auxiliary air gap are other gap3 and resistances, and resistances, and the ground neath from the last panel connection. The frame is of thoroughlydried wood, while glass or porcelain is recommend. ed for the upper end.

Several feet above these panels are the choke

coils, also on wooden frames, and with six coils in series with each leg of the three-phase lines. The coils are wound spirally about a wooden core, with no metal parts to cause induced current and lower the holing effect of the coils. Dach has five layers of has five layers of cotton tape, with seventen to nineteen complete layers. The choke coils are thoroughly soaked in insulat ing varnish and baked, and finally painted black. Where choke coils are used as in this case, they mus be connected in circuit between the apparatus to be protected and the arrester. In the same room are located the circuit-breakers, as well as the converter for the ammeters, which are in a panel in the transformer room. The circuit-breakers are high upon the wall, having a long drop lever to rupture the arc. The floors of the transformer and lightning arrester room are of cement. The high potential switches are operated by means of a long hardwood pole, having a hook in the end to engage in an eye near the end of

The high potential marble panels in the foreground formers. The converters for the high potential switchThe switches are double throw. The bus-bar porcelain insulators are thoroughly tested for 60,000 volts.

Illustration No. 3 shows the terminus of the high potential bus-bars and two sets of bus-bar double-throw switches. Illustration No. 4 gives a complete view of the Westinghouse transformers for the Union Carbide transmission lines. Upon the floor is shown a group of choke coils with their framework ready for mounting. The bus-bars for the transmission line are insulated with three layers of tape and two additional layers at the clamps, after being coated with insulating varnish and dried. This is then coated with liquid on the left of Fig. 1 receive the wires from the transboard ammeters are back the panels seen in Fig. 1.

50,000 volts. The insulators in the air chamber are thoroughly secured by screws or bolts to the iron framework of the place. Exceptional care should always be taken in installing wires and bus-bars for high-tension circuits. They should be out of reach, when possible, to avoid mechanical injury. To accomplish this, they are universally placed ten to twenty feet above the floor, and leave the power house at the highest possible point. They should be in plain view, and rigidly supported on porcelain insulators. These bus-bars as shown are supported upon insulators of special design. In the air-chamber, where the hightension cables from the transformers and from the high-tension panels cross each other, the crossing is effected in the most approved manner, special means being frequently necessitated.

Porcelain tubes are placed over each cable at the insulators, where iron brackets are in use. The cables are
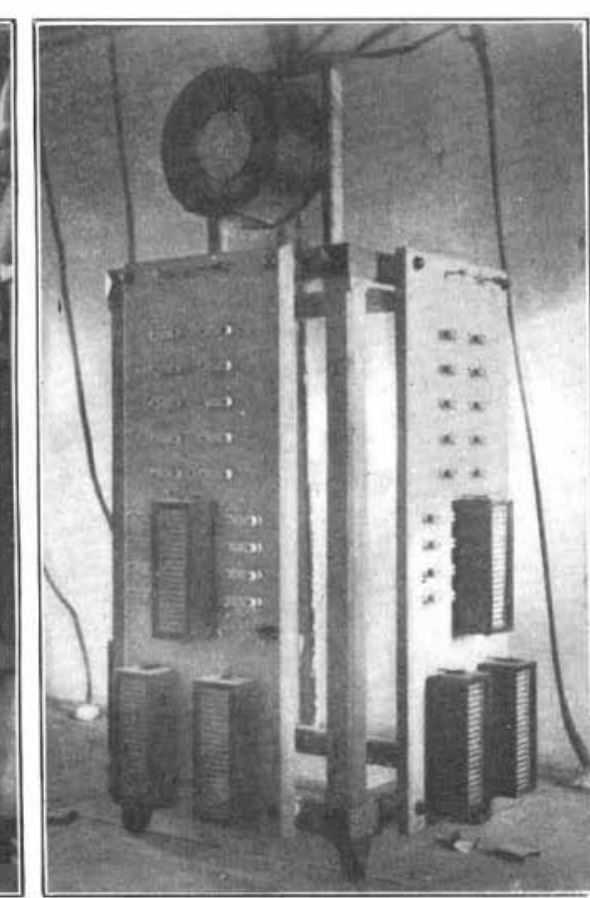

2.-Lightning Arresters.

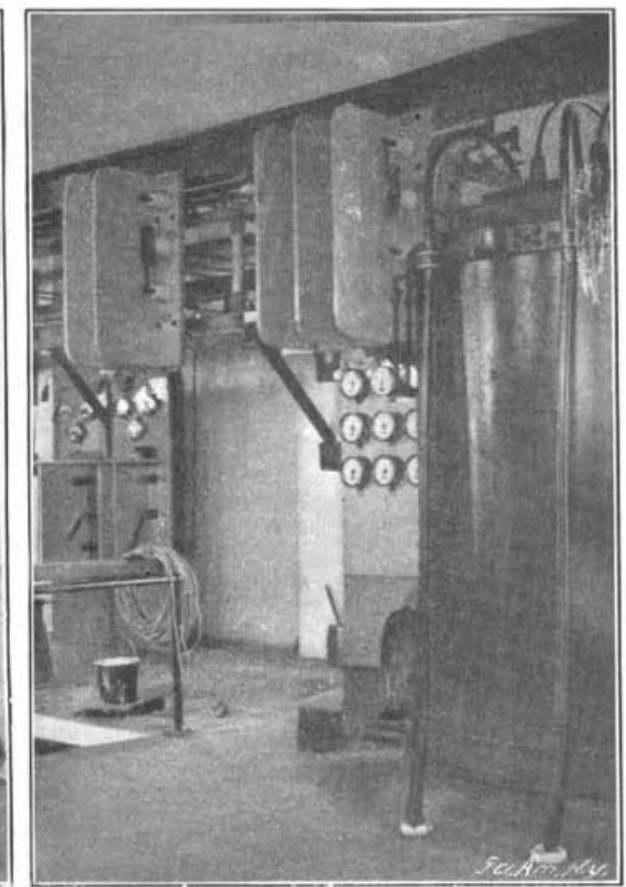

3.-Terminus of Hlgh Potential BusBars, and Double-Throw Switches. also run through porcelain tubes in the cemented the high - tension marble panels. With the introduction of the circuit - breakers on the high potential side, the time element circuit. breakers and fuses on the low potential side will potential side will ued, and the pan. els remodeled. If for any reason, the high potential circuit-breakers in the lightning ar rester room do not act under short circuit, the emergency switch upon the switchboard will be depended upon to open the dynamo field cir cuit-breakers. It is, however, hardly possible that recourse will have to be emergency switch.

The new step-up transformers for the Union Carbide Company, shown in illustration No. 4 , are of Westing house make, oi insulated and wainsulated and wa. ter cooled. Each is of 2,500 - horse power capacity. being twice as large as any others previously made. The cables from the power house switch boards are first connected to the low-tension panel at the right of the transforme room, and, after proper connec switches and cirswitches cuit-breakers, pas directly to the Cent developments at the niagara falls power plant ir low-tension sides glass and soapstone, and afterward painted black The framework is very neatly made, and substantial The bus-bar switches are double-throw, and when either side is cut out, the switch-blade is closed upon the center connection to prevent accidental closing The thick marble slabs effectually prevent arcing from blade to blade. The full capacity of the bus-bars, when complete, will be 25,000 horse power. The twenty General Electric air-blast transformers of 1,250 hors power each are all in place. The high potential switches are double throw; thus a line may be changed at will at either bus-bar.

The General Electric induction motors of eight horse power each, which have given excellent service in driving the blowers to cool the transformers, must owing to lack of space and the demand for increase ir supply, make way for two others of the same make of twenty-five horse power each. All the wiring is done in the most approved manner, and is tested with sides 11,000 volts three-phase. The cables are the connected to the high-tension panels at the left, from which they are carried in a subway to the works of the Union Carbide Company, a mile distant. lead-sheathed cables are used on these three transmission lines in the subway.

\section{Raising Hungarian Grapes.}

An experiment in raising Hungarian grapes is to be made near Norfolk, Va. Barth S. Lindsay of Norfolk Va., is the projector of this experiment. He will at first plant three acres in these vines, and if, after three years, the experiment proves a success, be will establish a larger vineyard. Mr. Lindsay, who has had experience as a vine-dresser in Hungary, considers the climate and soil of this section favorable to the growth of these grapes. transformers, which take on their low-tension sides 